\title{
Comparative effect of Fenugreek and Cinnamon on management of newly diagnosed cases of Type-2 Diabetes Mellitus
}

\author{
Hajra AHMAD ${ }^{1}$, Seemin $\mathrm{KASHIF}^{1}$, Asma AFREEN ${ }^{1}$, Mahpara SAFDAR $^{1}$, Zaheer AHMED ${ }^{1 \star}$ (i)
}

\begin{abstract}
Clinical evidence suggests that T2DM and its complications can be prevented through regular intake of functional foods. This cost-effective way of managing T2DM in developing world might prove very beneficial. A randomized controlled trial was done to compare effects of Fenugreek and Cinnamon on treatment of newly diagnosed cases of T2 DM. Subjects were selected from Pakistan Institute of Medical Sciences Hospital, Islamabad. Study was carried out in three phases: Phase I, baseline; Phase II, after 90 days and Pahse III at end of washout period. Subjects, from both genders, were within the age range of 40-65 years. There were 26 subjects in each group. Serum levels of FPG, HbAlc, fasting insulin levels, lipid profile were measured at baseline and at the end of 2nd and 3rd phases. BMI, WC and WHR were also studied in all phases of the study. SPSS (version 22) was used for analysis. Cinnamon seemed to have more effect on both anthropometric (BMI \& WC) and biochemical (FPG, HbAlc, serum Insulin, serum cholesterol, HDL \& LDL) parameters, as compared to Fenugreek, which had effect on WC, FPG, HbAlc, serum cholesterol and TG only. Although, the magnitude of these effects was similar in both groups.
\end{abstract}

Keywords: Cinnamon; Fenugreek; nutraceuticals for T2DM; biochemical markers.

Practical Application: The costs of Diabetes cause many financial problems to patients, healthcare systems, and insurers. In lowincome countries, prevalence of Diabetes is increasing, and both national and individual income levels are low. Hence, use of nutraceuticals can be recommended as an adjunct to medical management, in order to reduce the requirement of medication and hence reduce the cost of treatment.

\section{Introduction}

All foods which contain biologically active ingredients are considered to be functional foods because of their health benefits associated with prevention of certain NCDs like DM. Many studies focused on the herbal remedies which played role in the treatment of Diabetes (Acevedo et al., 2017; Choudhury et al., 2017; Shahzad et al., 2020). There were 451 million people with T2DM all over the world by year 2017, and this number was expected to rise to 693 million by year 2045 (Ogurtsova et al., 2017). About 5 million deaths all over the world were attributable to Diabetes in year 2017. According to second National Diabetes Survey of Pakistan (NDSP), conducted from February 2016 to August 2017, prevalence of Diabetes in Pakistan was 26.3\%, out of which $19.2 \%$ were known diabetics, and $7.1 \%$ were newly diagnosed cases(Basit et al., 2018). Clinical evidence suggests that $\mathrm{T} 2 \mathrm{DM}$ and its complications can be prevented through regular intake of functional foods (Alkhatib et al., 2017; Venkatakrishnan et al., 2019).

Cinnamon extract seems to contain substances which can upregulate glucose uptake, increase glycogen synthesis, inhibit glycogen breakdown, and reduce glucose absorption in the small gut through their effect on various enzymes (Ilijeva \& Buchbauer, 2016; Jahangir et al., 2017; Mollazadeh \& Hosseinzadeh, 2016; Muhammad \& Dewettinck, 2017). On the other hand, three components of Fenugreek, namely, Diosgenin, 4-hydroxyisoleucine (4-OHIle), and the fiber component, are the most studied bioactive fractions of the plant, which were found to exert beneficial effects on glucose tolerance, insulin function, inflammation, blood lipids, and liver functions (Avalos-Soriano et al., 2016; Ota \& Ulrih, 2017; Shi et al., 2017; Siener et al., 2020). Cinnamon supplements were found to have moderate effects on FPG and HbA1c, when added to standard hypoglycemic medications (Costello et al., 2016). A systematic review found that supplementation with cinnamon could decrease serum levels of glucose, without changes in other glycemic and anthropometric indices (Namazi et al., 2019). Literature review also suggested that cinnamon could be recommended as effective therapy to reduce fasting glucose levels and HbAlc levels in type II diabetics. For this purpose, cinnamon dose could range from $1 \mathrm{~g}$ to $6 \mathrm{~g}$ daily with meals (Ge et al., 2017; Maddox, 2016) randomized controlled trial found that intake of $1 \mathrm{~g}$ of cinnamon for 12 weeks could decrease fasting blood glucose and $\mathrm{HbAlc}$ among uncontrolled type 2 diabetes patients (Sahib, 2016). In another study, diabetic patients were supplemented with one gram of cinnamon daily. This resulted in improvement of BMI, glycemic indices (i.e. fasting glucose, 2 hours PP, $\mathrm{HbAlC}$, fasting insulin, and insulin resistance), and lipid profile (i.e. total cholesterol, LDL and HDL) in the cinnamon group, when compared with the placebo group. All these changes were more prominent in patients who had $\mathrm{BMI} \geq 27$. Hence inconsistency of results amongst various studies were thought to be due to the 
difference in doses and duration of intervention as well as due to difference in baseline BMI (Zare et al., 2019).

Fenugreek was also found to have hypoglycemic and cholesterollowering effect (Gong, J., et al., 2016). Fenugreek extract was found to cause significant reduction in fasting plasma glucose and post-prandial blood glucose levels (Verma et al., 2016). A study showed that adjunct therapy of a standardized fenugreek seed extract (IND-2) with insulin in T2DM patients improved blood glucose control through a reduction in levels of $\mathrm{HbAlc}$ and also through reduction of insulin doses per day, without any increase in risk of hypoglycemia and body weight (Kandhare et al., 2018). Another standardized fenugreek seed extract (IDM1) was also found to be an effective adjuvant therapy with sulphonylurea, which helped to control blood sugar levels and HbA1c levels in those T2DM patients in which these parameters were inadequately controlled with sulfonylurea alone (Kandhare et al., 2018). In rat models, the aqueous sprout extracts from IL8 Fenugreek seed genotype showed much higher hypoglycemic activity as compared to its seed extract. This antidiabetic effect of sprout extracts was found to be comparable to standard antidiabetic drug, Voglibiose (Laila et al., 2016). Another study showed that consumption of sprouted fenugreek seeds had significant effects on improving blood glucose levels, BMI, and BP in type II diabetic patients (Khan \& Khosla, 2018). Thus, Fenugreek can be possibly used as a complementary therapy to anti-diabetic drugs, in order to control blood glucose (Najdi et al., 2019). As per literature now study has been conducted on Pakistani diabetic population. Keeping in mind above scenario current study has been designed to study the comparative impact of fenugreek and background impact of above mentioned two nutraceuticals Fenugreek and Cinnamon.

\section{Materials and methods}

A Randomized Controlled Trial (RCT) was done to compare the effects of Fenugreek and Cinnamon on management of newly diagnosed cases of Type2 DM. The study was conducted at Medical Outpatient Department (OPD) of Pakistan Institute of Medical Sciences (PIMS), which is a tertiary care hospital, located in Islamabad, capital of Pakistan. Subjects were enrolled for the study after fulfilling all ethical considerations.

All subjects, from both genders, fell within the age range of 40-65 years. All were newly diagnosed cases of T2DM. They were diagnosed diabetic on the basis of fasting plasma glucose (FPG), in accordance with the criteria given by American Diabetes Association (2014). Twenty-six (26) subjects were allotted to each group (Figure 1). Baseline data included assessment of nutritional status, biochemical data, physical examination, diet history, information related to ethnicity, age, education, family history of diabetes, occupation, physical activity level, sleeping habits, and history of smoking. Anthropometric measurements included BMI (Body mass index), WC (waist circumference), and WHR (waist-to-hip ratio). Biochemical tests included FPG (Fasting Plasma Glucose), HbA1c (Hemoglobin A1c), fasting insulin levels, lipid profile (total cholesterol, high density lipoproteins (HDL), low density lipoproteins (LDL), very lowdensity lipoproteins (VLDL) and serum triglycerides (TG). Subjects were studied in three phases. Phase-1 was the baseline,

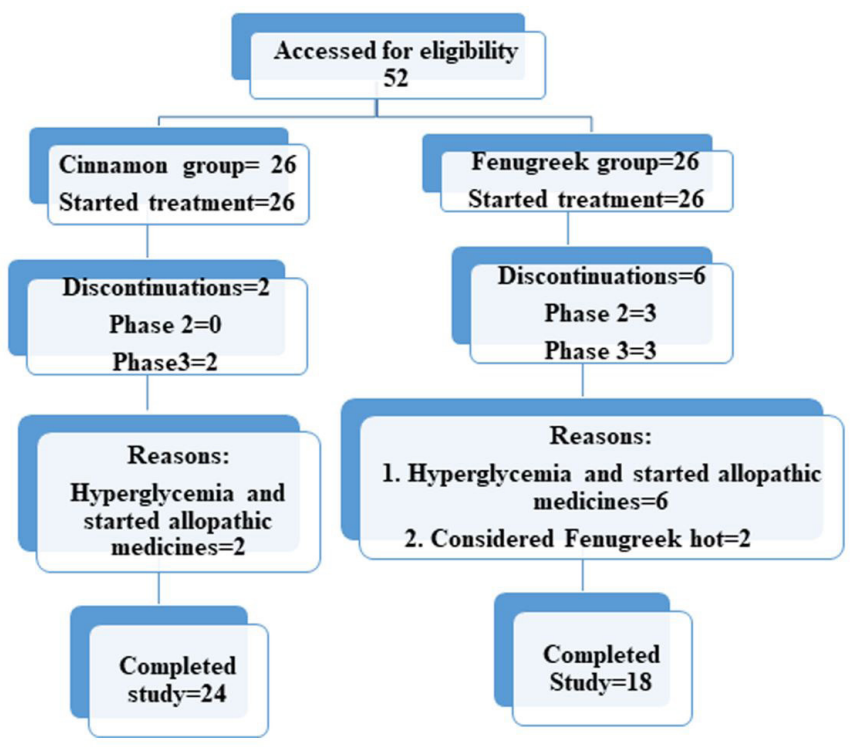

Figure 1. Flow diagram of the participants of the study.

at the start of intervention. Phase- 2 was at the end of 90 days of intervention i.e., treatment with Fenugreek and cinnamon. In second phase, counseling for diet \& life style modification was also done. Phase- 3 was the phase after one month of stopping the intervention. It was considered to be the washout period. At the end of phase 2 and phase 3 , all these tests were repeated to find out any difference in pre- and post-intervention findings. Anthropometry, biochemical, clinical and dietary aspects were also studied in all phases of the study to evaluate effect of intervention.

Treatments were prepared in the form of powders and packed in capsules before being dispensed to the patients as depicted below:

1. Cinnamon group: 4.0 grams cinnamon powder/day, was divided into three doses of $3+3+2$ capsules, after each main meal i.e., breakfast, lunch and dinner. Each capsule had 500mg of cinnamon powder;

2. Fenugreek group: 20 grams powder/day, was divided into four doses of $10+10+10+10$ capsules, after breakfast, lunch, evening snack and dinner.

Statistical analysis was done on SPSS (version 22). Descriptive analysis was done for percentages and means. Paired-sample T-tests and Independent sample T-tests were done to compare the effects of interventions. A p-value $<0.05$ was considered significant.

\section{Results and discussion}

There were dropouts from both groups by the end of study, i.e., 2 from cinnamon and 8 from fenugreek, on account of poor control of glucose levels and food taboos (Figure 1).

\subsection{Gender-wise distribution of the subjects}

The study groups had $32(61.5 \%)$ male participants and $20(38.5 \%)$ female participants in all $(n=52)$ (Figure 2A). 
Age group, highest in percentage, was $45-55$ years (44\%). Rest of the participants were below (40-45 years, $16 \%)$ and above (55-65 years, $13 \%$ ) this age group (Figure 2B).

\subsection{Comparison of anthropometric measurements during all phases of intervention}

Mean BMI of male participants at baseline in Cinnamon group was $25.64 \mathrm{~kg} / \mathrm{m}^{2}$, while mean BMI of female participants in this group was $31.01 \mathrm{~kg} / \mathrm{m}^{2}$. At the end of treatment, BMI of male and female participants reduced to $24.65 \mathrm{~kg} / \mathrm{m}^{2}$ and $29.71 \mathrm{~kg} / \mathrm{m}^{2}$, respectively. This result was consistent with a study which showed reduction in BMI when one gram daily dose of cinnamon was used for intervention (Zare et al., 2019). After washout period, BMI increased to $24.78 \mathrm{~kg} / \mathrm{m}^{2}$ and $30.93 \mathrm{~kg} / \mathrm{m}^{2}$ in males and females, respectively (Figure $3 \mathrm{~A}, \mathrm{~B}$ ). While in Fenugreek group, mean BMI of male participants at baseline was $28.09 \mathrm{~kg} / \mathrm{m}^{2}$, and in female participants BMI was $28.96 \mathrm{~kg} / \mathrm{m}^{2}$, respectively. At the end of treatment, BMI increased to $28.15 \mathrm{~kg} / \mathrm{m}^{2}$ in males and to $29.63 \mathrm{~kg} / \mathrm{m}^{2}$ in female participants, but after washout period, BMI was reduced to $27.64 \mathrm{~kg} / \mathrm{m}^{2}$ in females, and increased to $29.75 \mathrm{~kg} / \mathrm{m}^{2}$ in females. This result was inconsistent with literature which showed improvement in BMI with use of Fenugreek (Khan \& Khosla, 2018).

Similarly, mean waist circumference (WC) and waist-to-hip ratio (WHR) of both male and female participants in Cinnamon group, reduced in both male and female participants after treatment. After washout period, WC reduced further, but WHR bounced back in males, while in females, WC and WHR increased (Figure 3C and 3E). Mean waist circumference (WC) of male participants was reduced after treatment, in Fenugreek group, but WHR remained same in males, and both WC and WHR were reduced in female participants. After washout period, WC reduced further, but WHR increased in males, while both WC and WHR increased, in females (Figure 3D-F). Though variable beneficial effects of these nutraceuticals were found on WC and WHR in this study, no such effects were found in literature.

\subsection{Comparison of biochemical markers during all phases of intervention}

In Cinnamon group, mean Fasting Plasma Glucose (FPG) in males, at baseline, was $152.38 \mathrm{mg} / \mathrm{dL}$, and in females was $160.31 \mathrm{mg} / \mathrm{dL}$. It reduced after treatment in both males and females. FBS reduced further in both males and females, at the end of washout period (Table 1). Similarly, in Fenugreek group, mean FPG in males, at baseline, was $154.79 \mathrm{mg} / \mathrm{dL}$, and in females was $139.29 \mathrm{mg} / \mathrm{dL}$, which reduced in both males and females after treatment. FBS reduced further in both males and females at the end of washout period (Table 1). Many studies had shown beneficial effects of Cinnamon and Fenugreek on FPG (Maddox, 2016; Verma et al., 2016).

In Cinnamon group, $\mathrm{HbA1c} \%$ age reduced in both males and females after treatment phase. It reduced further in both genders after washout period. Similarly, in Fenugreek group, $\mathrm{HbAlc} \%$ age reduced in both male and female participants after treatment (Table 1). Although after washout period, it reduced further in male group, but increased again in female participants. These findings were consistent with many findings in literature (Kandhare et al., 2018; Maddox, 2016; Sahib, 2016). Mean Insulin levels also decreased in both male and female participants, in both intervention groups. It kept falling in washout period in all these groups, except in female participants in Fenugreek group. This finding was consistent with literature in regard to Cinnamon, but no such positive finding was reported in case of Fenugreek (Zare et al., 2019). Serum cholesterol level was found to decrease in both treatment and washout periods, in both intervention groups, in both genders. On the other hand, serum HDL was found to increase in both treatment and washout periods, in both intervention groups, in both genders (Table 1). Serum LDL decreased in both treatment and washout periods, in both Cinnamon and Fenugreek groups, in both male and female participants, except for male group in Fenugreek group, where the level of LDL bounced up in washout period. Serum VLDL decreased in both genders in Cinnamon group after

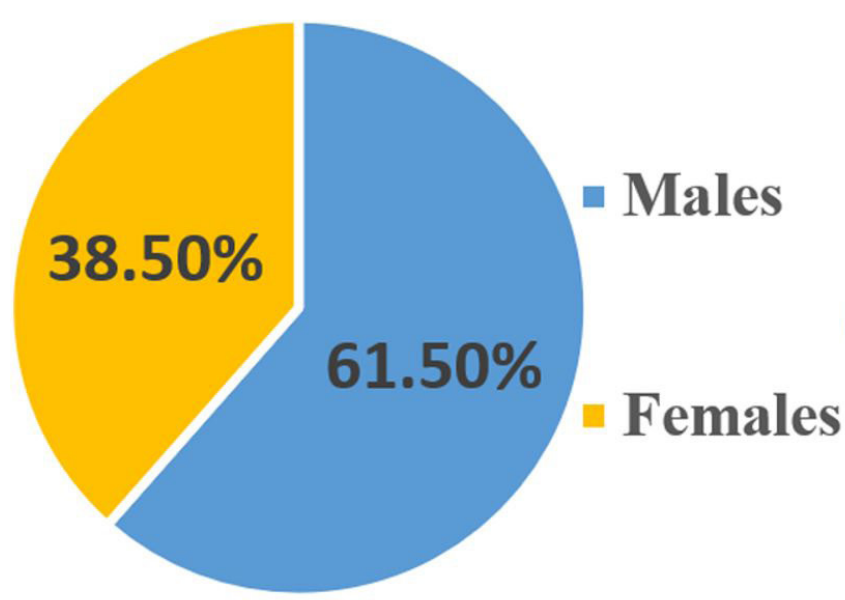

(A)

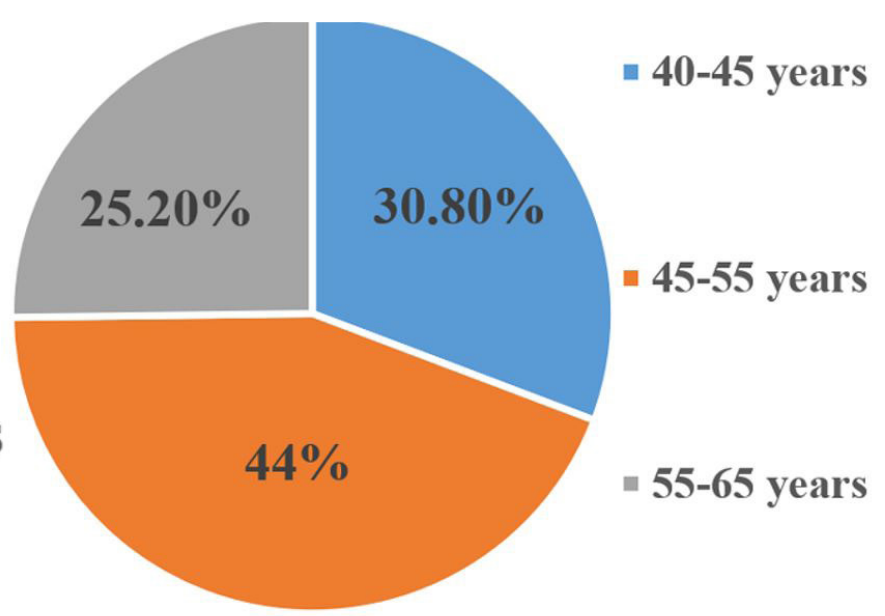

(B)

Figure 2. (A) Gender distribution (B) Age distribution. 


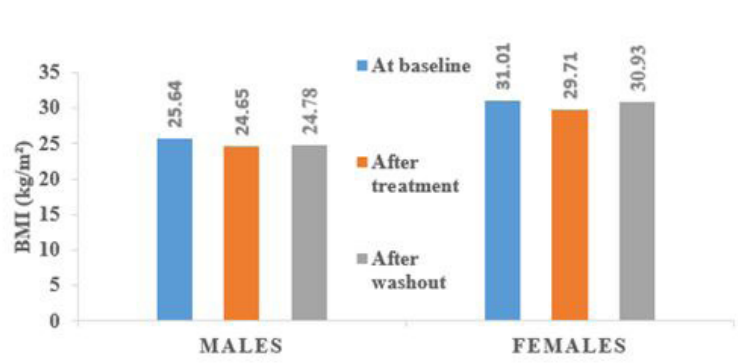

(A)

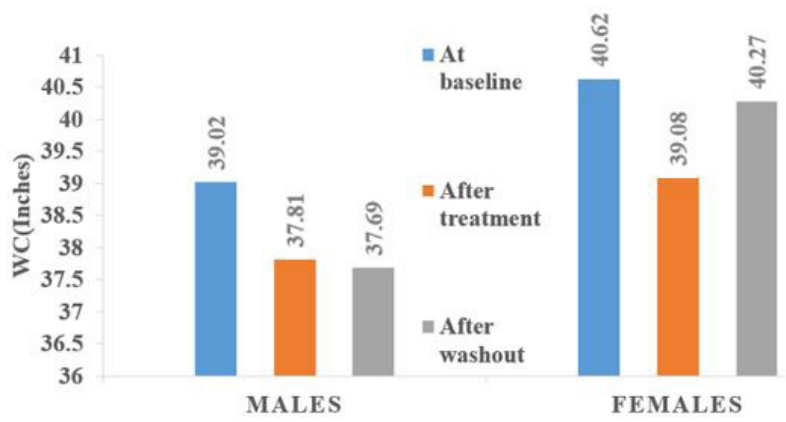

(C)

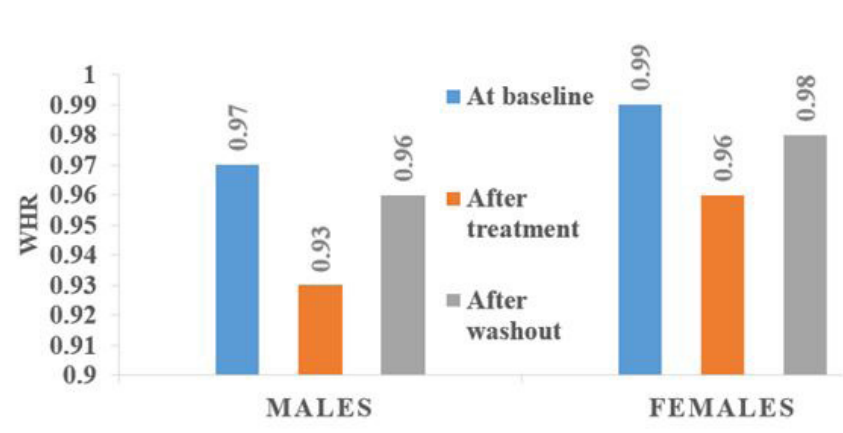

(E)

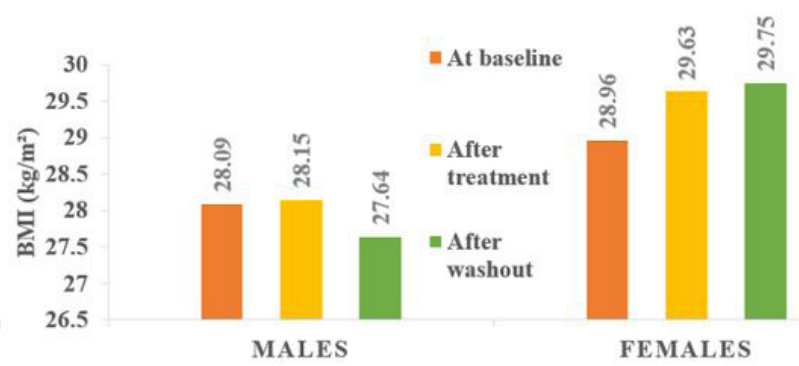

(B)

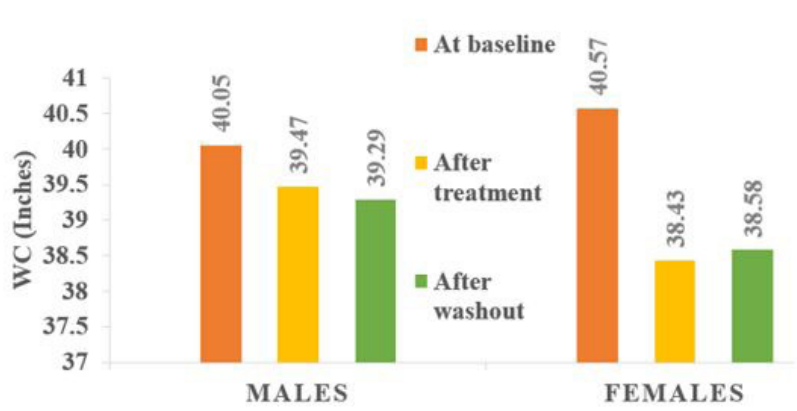

(D)

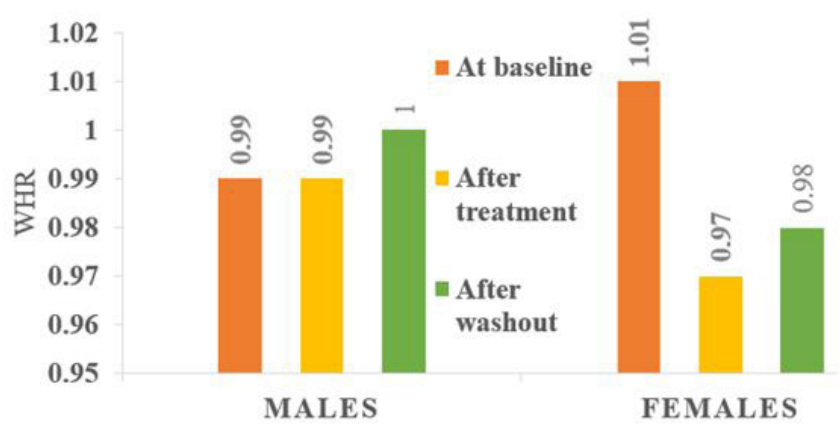

(F)

Figure 3. Body Mass Index (BMI) of study subjects: (A) Cinnamon group (B) Fenugreek group; Waist Circumferences (WC) of study subjects: (C) Cinnamon group (D) Fenugreek group; Waist Hip Ratio of study subjects: (E) Cinnamon group (F) Fenugreek group.

treatment and remained the same after washout period. On the other hand, in Fenugreek group, it increased in male group, and stayed high even after washout period, but in female group, it decreased and remained low after washout period. Serum TG (serum triglyceride) levels decreased in Fenugreek group in both genders, and in female group in Cinnamon group, after treatment, and increased again in washout period, but it increased in male group, in Cinnamon group, and then fell back after washout period Once again this finding was consistent with literature when Cinnamon was considered, but it was a new finding in regard to Fenugreek (Zare et al., 2019).

In summary, the results showed significant effect of Cinnamon and Fenugreek intervention on various biochemical parameters. FPG and HbA1c fell significantly in both groups, but Insulin level fell significantly only in Cinnamon group. Cholesterol level fell in both groups, HDL increased and LDL fell significantly only in Cinnamon group, and TG level fell only in Fenugreek group.
Paired-sample t-test was run on means of measures of both interventional groups as a whole (i.e. including both genders), at baseline and after-treatment. Significant differences were found between mean values of many anthropometric and biochemical measures. There was statistically significant difference in BMI in Cinnamon group after intervention, but no such difference was found in Fenugreek group. Significant difference was found in WC in both intervention groups, but no significant difference was found in WHR. FPG and HbA1c showed statistically significant difference after intervention in both groups, but Insulin level fell significantly only in Cinnamon group. Serum Cholesterol level fell significantly in both groups, but LDL level fell significantly only in Cinnamon group. Similarly, serum triglycerides level fell significantly only in Fenugreek group, but rather increased insignificantly in Cinnamon group. Serum HDL level increased significantly in Cinnamon group, but not in Fenugreek group. No statistically significance was found in levels of VLDL in both 
Table 1. Comparison of Biochemical marker level in both groups, in all phases of intervention.

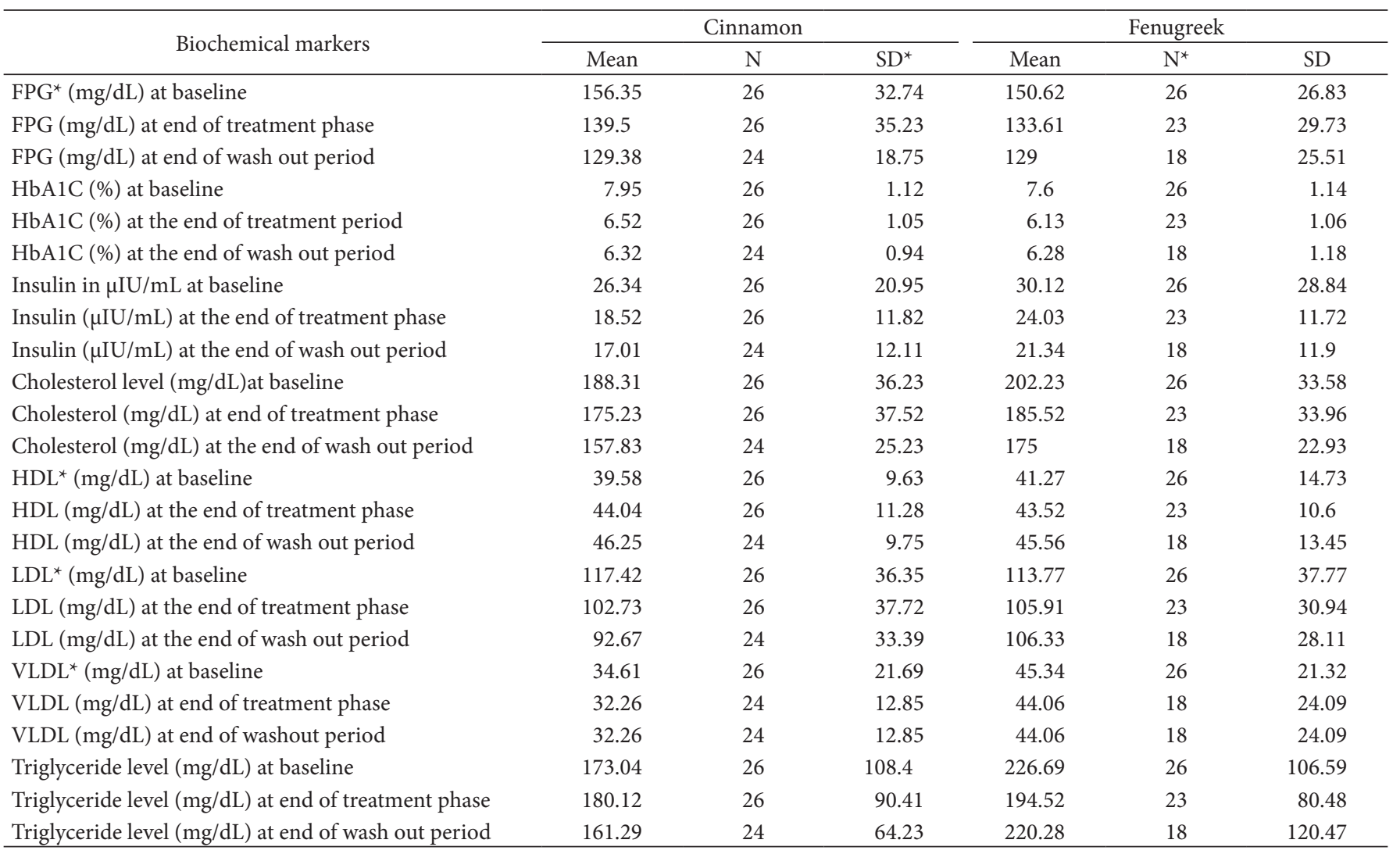

SD*: Standard Deviation; $N^{*}$ : Number; FPG: Fasting Plasma Glucose; HDL: High-density lipoprotein; LDL: Low-density lipoprotein; VLDL: Very low-density lipoprotein. HbAlc: glycated haemoglobin

groups. When Independent- sample T-test was done, statistically significant difference was found only in levels of VLDL after treatment (Table 2).

Hence, when results of treatment were compared between both groups, no significant difference was found in any anthropometric measure, reflecting that wherever there was significant effect of both interventions on same parameter, it was of similar magnitude. Similarly, Independent-sample tests showed change of similar magnitude in both groups, in regard to FPG, HbA1c and Insulin levels. The changes in cholesterol level, HDL, LDL, and TG levels were also similar in magnitude in both groups, as no statistically significant difference was found when independent sample means were compared. VLDL did not change significantly in any group.

The costs of Diabetes present huge financial problems to patients, healthcare systems, and insurers (Riddle \& Herman, 2018). The average monthly medical expenditure has been found to be significantly higher for households who were on Diabetes medication, as compared to households who were not (Datta et al., 2019). The healthcare expenditure on Diabetic patients all over the world by year 2017 was 850 billion US dollars (Ogurtsova et al., 2017). In USA, more than 29 million people have Diabetes and this costs US healthcare system 245 billion dollars annually (Sai Ambati et al., 2019; Willey et al., 2018). Enough data, regarding expenditure on Diabetes treatment, does not exist in low-income countries, where prevalence of Diabetes is increasing, and incomes at both national and individual levels are low. Wherever such data exists, it suggests that use of medical care associated with Diabetes is not within reach for many patients (Williams et al., 2020). Hence, use of functional foods can be recommended as adjunct to medical treatment to reduce the requirement of medication and hence reduce the cost of treatment.

\section{Conclusion}

Cinnamon seemed to have more effect on both anthropometric (BMI \& WC) and biochemical (FPG, HbAlc, serum Insulin, serum cholesterol, HDL \& LDL) parameters, as compared to Fenugreek, which had effect on WC, FPG, HbAlc, serum cholesterol and TG only. Although, the magnitude of these effects was similar in both groups. Its concluded that the use of natural nutraceuticals may help in managing the sugar level of newly diagnosed patient. Especially study finding can help to rural community where people are reluctant to use the allopathic medicine for treating the diabetes.

\section{Acknowledgements}

We are thankful to the management of Pakistan Institute of Medical Sciences, particularly Head of the Department of Medicine for facilitating in data collection from their premises. 
Original Article

Effect of Fenugreek and Cinnamon on management of T2DM

Table 2. Paired Statistics for anthropometric measures \& biochemical markers in both groups.

\begin{tabular}{|c|c|c|c|c|c|}
\hline & & Mean & $\mathrm{N}^{*}$ & $\mathrm{SD}^{*}$ & p-value \\
\hline \multirow{2}{*}{ Cinnamon group: } & BMI (in $\mathrm{kg} / \mathrm{m}^{2}$ ) at baseline & 28.32 & 26 & 6.20 & \multirow{2}{*}{0.000} \\
\hline & BMI (in $\mathrm{kg} / \mathrm{m}^{2}$ ) at the end of treatment phase & 27.18 & 26 & 5.61 & \\
\hline \multirow{2}{*}{ Fenugreek group } & BMI (in $\mathrm{kg} / \mathrm{m}^{2}$ ) at baseline & 27.42 & 23 & 4.86 & \multirow{2}{*}{0.342} \\
\hline & $\mathrm{BMI}\left(\right.$ in $\mathrm{kg} / \mathrm{m}^{2}$ ) at the end of treatment phase & 28.60 & 23 & 4.03 & \\
\hline \multirow{2}{*}{ Cinnamon group: } & WC (in inches) at baseline & 39.82 & 26 & 4.79 & \multirow{2}{*}{0.001} \\
\hline & WC (in inches) at the end of treatment phase & 38.44 & 26 & 4.05 & \\
\hline \multirow{2}{*}{ Fenugreek group } & WC (in inches) at baseline & 40.48 & 23 & 3.60 & \multirow{2}{*}{0.001} \\
\hline & WC (in inches) at the end of treatment phase & 39.15 & 23 & 3.35 & \\
\hline \multirow{2}{*}{ Cinnamon group: } & FPG (in $\mathrm{mg} / \mathrm{dl}$ ) at the end of treatment phase & 156.35 & 26 & 32.73 & \multirow{2}{*}{0.028} \\
\hline & FPG (in $\mathrm{mg} / \mathrm{dL}$ ) at the end of treatment phase & 139.50 & 26 & 35.22 & \\
\hline \multirow{2}{*}{ Fenugreek group } & FPG (in $\mathrm{mg} / \mathrm{dL}$ ) at baseline & 145.61 & 23 & 22.25 & \multirow{2}{*}{0.029} \\
\hline & FPG (in $\mathrm{mg} / \mathrm{dL}$ ) at the end of treatment phase & 133.61 & 23 & 29.73 & \\
\hline \multirow{2}{*}{ Cinnamon group: } & $\mathrm{HbA} 1 \mathrm{C}$ percent at baseline & 7.95 & 26 & 1.12 & \multirow{2}{*}{0.000} \\
\hline & $\mathrm{HbA} 1 \mathrm{C}$ percent at the end of treatment period & 6.52 & 26 & 1.05 & \\
\hline \multirow{2}{*}{ Fenugreek group } & HbA1C percent at baseline & 7.64 & 23 & 1.02 & \multirow{2}{*}{0.000} \\
\hline & $\mathrm{HbA1C}$ percent at the end of treatment period & 6.13 & 23 & 1.06 & \\
\hline \multirow{2}{*}{ Cinnamon group: } & Insulin (in $\mu \mathrm{IU} / \mathrm{mL}$ ) at baseline & 26.34 & 26 & 20.95 & \multirow{2}{*}{0.020} \\
\hline & Insulin (in $\mu \mathrm{IU} / \mathrm{mL}$ ) at the end of treatment phase & 18.52 & 26 & 11.82 & \\
\hline \multirow{2}{*}{ Fenugreek group } & Insulin in $\mu \mathrm{IU} / \mathrm{mL}$ at baseline & 30.38 & 23 & 29.89 & \multirow{2}{*}{0.305} \\
\hline & Insulin in $\mu \mathrm{IU} / \mathrm{mL}$ at the end of treatment phase & 24.03 & 23 & 11.72 & \\
\hline \multirow{2}{*}{ Cinnamon group: } & Cholesterol level (in $\mathrm{mg} / \mathrm{dL}$ ) at baseline & 188.31 & 26 & 36.23 & \multirow{2}{*}{0.025} \\
\hline & Cholesterol level(in $\mathrm{mg} / \mathrm{dL}$ ) at the end of treatment phase & 175.23 & 26 & 37.52 & \\
\hline \multirow{2}{*}{ Fenugreek group } & Cholesterol level at baseline & 201.65 & 23 & 35.45 & \multirow{2}{*}{0.004} \\
\hline & Cholesterol level at the end of treatment phase & 185.52 & 23 & 33.96 & \\
\hline \multirow{2}{*}{ Cinnamon group: } & $\mathrm{HDL}$ (in $\mathrm{mg} / \mathrm{dL}$ ) at baseline & 39.58 & 26 & 9.63 & \multirow[t]{2}{*}{0.014} \\
\hline & $\mathrm{HDL}$ (in $\mathrm{mg} / \mathrm{dL}$ ) at the end of treatment phase & 44.04 & 26 & 11.28 & \\
\hline \multirow{2}{*}{ Fenugreek group } & $\mathrm{HDL}$ (in $\mathrm{mg} / \mathrm{dL}$ ) at baseline & 40.83 & 23 & 15.58 & \multirow{2}{*}{0.237} \\
\hline & HDL (in $\mathrm{mg} / \mathrm{dL}$ ) at the end of treatment phase & 43.52 & 23 & 10.60 & \\
\hline Cinnamon aroun. & $\mathrm{LDL}$ (in $\mathrm{mg} / \mathrm{dL}$ ) at baseline & 117.42 & 26 & 36.35 & 0043 \\
\hline Cinnamon group: & $\mathrm{LDL}$ (in $\mathrm{mg} / \mathrm{dL}$ ) at the end of treatment phase & 102.73 & 26 & 37.72 & 0.043 \\
\hline Fenuoreek oroun & LDL at baseline & 111.52 & 23 & 39.51 & 0218 \\
\hline & LDL at the end of treatment phase & 105.91 & 23 & 30.94 & \\
\hline Cinnamon aroun. & Triglyceride level (in $\mathrm{mg} / \mathrm{dL}$ ) at baseline & 173.04 & 26 & 108.45 & 0723 \\
\hline cimmamon group: & Triglyceride level (in $\mathrm{mg} / \mathrm{dL}$ ) at the end of treatment phase & 180.12 & 26 & 90.41 & 0.120 \\
\hline & Triglyceride level (in $\mathrm{mg} / \mathrm{dL}$ ) at baseline & 234.09 & 23 & 110.46 & \\
\hline Fenugreek group & Triglyceride level (in $\mathrm{mg} / \mathrm{dL}$ ) at the end of treatment phase & 194.52 & 23 & 80.48 & 0.003 \\
\hline
\end{tabular}

SD: Standard Deviation; N: Number; BMI: Body Mass Index; WC: Waist Circumferences; FPG: Fasting Plasma Glucose; HDL: High-density lipoprotein; LDL: Low-density lipoprotein; VLDL: Very low-density lipoprotein BMI: Body mass index WC: Waist circumference

\section{References}

Acevedo, M. E., Cerda, R. E. B., Rodriguez, R. M., Trevino, A., Gallegos, C. F., \& Charles, A. V. (2017). Functional foods tested in vivo and in vitro as a complement or substitution in the pharmacological treatment of diabetes. Scientific Journal of Food Science \& Nutrition, 3(11).

Alkhatib, A., Tsang, C., Tiss, A., Bahorun, T., Arefanian, H., Barake, R., Khadir, A., \& Tuomilehto, J. (2017). Functional foods and lifestyle approaches for diabetes prevention and management. Nutrients, 9(12), 1310. http://dx.doi.org/10.3390/nu9121310. PMid:29194424.

American Diabetes Association - ADA. (2014). Executive summary: standards of medical care in diabetes - 2014. Arlington: ADA.

Avalos-Soriano, A., Dela Cruz-Cordero, R., Rosado, J. L., \& Garcia-Gasca, T. (2016). 4-Hydroxyisoleucine from fenugreek (Trigonella foenum-graecum): effects on insulin resistance associated with obesity. Molecules, 21(11), 1596. http://dx.doi.org/10.3390/molecules21111596. PMid:27879673.
Basit, A., Fawwad, A., Qureshi, H., \& Shera, A. (2018). Prevalence of diabetes, pre-diabetes and associated risk factors: second National Diabetes Survey of Pakistan (NDSP), 2016-2017. BMJ Open, 8(8), e020961. http://dx.doi.org/10.1136/bmjopen-2017-020961. PMid:30082350.

Choudhury, H., Pandey, M., Hua, C. K., Mun, C. S., Jing, J. K., Kong, L., Ern, L. Y., Ashraf, N. A., Kit, S. W., Yee, T. S., Pichika, M. R., Gorain, B., \& Kesharwani, P. (2017). An update on natural compounds in the remedy of diabetes mellitus: A systematic review. Journal of Traditional and Complementary Medicine, 8(3), 361-376. http:// dx.doi.org/10.1016/j.jtcme.2017.08.012. PMid:29992107.

Costello, R. B., Dwyer, J. T., Saldanha, L., Bailey, R. L., Merkel, J., \& Wambogo, E. (2016). Do cinnamon supplements have a role in glycemic control in type 2 diabetes? A narrative review. Journal of the Academy of Nutrition and Dietetics, 116(11), 1794-1802. http:// dx.doi.org/10.1016/j.jand.2016.07.015. PMid:27618575. 
Datta, B. K., Husain, M. J., \& Asma, S. (2019). Assessing the relationship between out-of-pocket spending on blood pressure and diabetes medication and household catastrophic health expenditure: evidence from Pakistan. International Journal for Equity in Health, 18(1), 9. http://dx.doi.org/10.1186/s12939-018-0906-x. PMid:30646905.

Ge, Q., Chen, L., \& Chen, K. (2017). Treatment of diabetes mellitus using iPS cells and spice polyphenols. Journal of Diabetes Research, 2017, 5837804. http://dx.doi.org/10.1155/2017/5837804. PMid:28758131.

Ilijeva, R., \& Buchbauer, G. (2016). Biological properties of some volatile phenylpropanoids. Natural Product Communications, 11(10), 1619. http://dx.doi.org/10.1177/1934578X1601101041. PMid:30549629.

Jahangir, M. A., Shehzad, A., Butt, M. S., \& Shahid, M. (2017). Therapeutic potential of cinnamomum zeylanicum extract to mitigate hyperglycemia. Annals of King Edward Medical University, 23(2). http://dx.doi.org/10.21649/akemu.v23i2.1586.

Kandhare, A., Phadke, U., Mane, A., Thakurdesai, P., \& Bhaskaran, S. (2018). Add-on therapy of herbal formulation rich in standardized fenugreek seed extract in type 2 diabetes mellitus patients with insulin therapy: an efficacy and safety study. Asian Pacific Journal of Tropical Biomedicine, 8(9), 446. http://dx.doi.org/10.4103/2221-1691.242288.

Khan, F., \& Khosla, P. (2018). To study the effect of sprouted fenugreek seeds as nutraceutical as an add-on therapy in patients of diabetes mellitus, obesity and metabolic syndrome. Pharmacy \& Pharmacology International Journal, 6(4), 320-327. http://dx.doi.org/10.15406/ ppij.2018.06.00195.

Laila, O., Murtaza, I., Abdin, M., \& Showkat, S. (2016). Germination of fenugreek seeds improves hypoglycaemic effects and normalizes insulin signilling pathway efficiently in diabetes. International Journal of Pharmaceutical Sciences and Research, 7(4), 1535.

Maddox, P. J. (2016). Cinnamon in the treatment of Type II diabetes. Journal of Interdisciplinary Graduate Research, 2, 2-20.

Mollazadeh, H., \& Hosseinzadeh, H. (2016). Cinnamon effects on metabolic syndrome: a review based on its mechanisms. Iranian Journal of Basic Medical Sciences., 19(12), 1258-1270. PMid:28096957.

Muhammad, D. R. A., \& Dewettinck, K. (2017). Cinnamon and its derivatives as potential ingredient in functional food: a review. International Journal of Food Properties, 20(Suppl 2), 2237-2263. http://dx.doi.org/10.1080/10942912.2017.1369102.

Najdi, R. A., Hagras, M. M., Kamel, F. O., \& Magadmi, R. M. (2019). A randomized controlled clinical trial evaluating the effect of Trigonella foenum-graecum (fenugreek) versus glibenclamide in patients with diabetes. African Health Sciences, 19(1), 1594-1601. http://dx.doi. org/10.4314/ahs.v19i1.34. PMid:31148988.

Namazi, N., Khodamoradi, K., Khamechi, S. P., Heshmati, J., Ayati, M. H., \& Larijani, B. (2019). The impact of cinnamon on anthropometric indices and glycemic status in patients with type 2 diabetes: A systematic review and meta-analysis of clinical trials. Complementary Therapies in Medicine, 43, 92-101. http://dx.doi.org/10.1016/j. ctim.2019.01.002. PMid:30935562.

Ogurtsova, K., Rocha Fernandes, J., Huang, Y., Linnenkamp, U., Guariguata, L., Cho, N. H., Cavan, D., Shaw, J. E., \& Makaroff, L. E. (2017). IDF Diabetes Atlas: Global estimates for the prevalence of diabetes for 2015 and 2040. Diabetes Research and Clinical Practice, 128, 40-50. http://dx.doi.org/10.1016/j.diabres.2017.03.024. PMid:28437734.
Ota, A., \& Ulrih, N. P. (2017). An overview of herbal products and secondary metabolites used for management of type two diabetes. Frontiers in Pharmacology, 8, 436. http://dx.doi.org/10.3389/ fphar.2017.00436. PMid:28729836.

Riddle, M. C., \& Herman, W. H. (2018). The cost of diabetes care: an elephant in the room. Diabetes Care, 41(5), 929-932. http://dx.doi. org/10.2337/dci18-0012. PMid:29678864.

Sahib, A. S. (2016). Anti-diabetic and antioxidant effect of cinnamon in poorly controlled type-2 diabetic Iraqi patients: a randomized, placebocontrolled clinical trial. Journal of Intercultural Ethnopharmacology, 5(2), 108-113. http://dx.doi.org/10.5455/jice.20160217044511. PMid:27104030.

Sai Ambati, L., El-Gayar, O., \& Nawar, N. (2019). Understanding the influence of digital divide and socio-economic factors on the prevalence of diabetes. In Annual Research Symposium. Madison: Dakota State University.

Shahzad, S. A., Hussain, S., Mohamed, A. A., Alamri, M. S., Qasem, A. A. A., Ibraheem, M. A., Almaiman, S. A. M., \& El-Din, M. F. S. (2020). Gluten-free cookies from sorghum and Turkish beans; effect of some non-conventional and commercial hydrocolloids on their technological and sensory attributes. Food Science and Technology. In press. http://dx.doi.org/10.1590/fst.25419.

Shi, X., Miyakawa, T., Nakamura, A., Hou, F., Hibi, M., Ogawa, J., Kwon, Y., \& Tanokura, M. (2017). Engineering a short-chain dehydrogenase/ reductase for the stereoselective production of (2 S, $3 \mathrm{R}, 4 \mathrm{~S})-4$ hydroxyisoleucine with three asymmetric centers. Scientific Reports, 7(1), 13703. http://dx.doi.org/10.1038/s41598-017-13978-w.

Siener, R., Seidler, A., \& Hönow, R. (2020). Oxalate-rich foods. Food Science and Technology. In press. http://dx.doi.org/10.1590/fst.10620.

Venkatakrishnan, K., Chiu, H.-F., \& Wang, C.-K. (2019). Popular functional foods and herbs for the management of type-2-diabetes mellitus: a comprehensive review with special reference to clinical trials and its proposed mechanism. Journal of Functional Foods, 57, 425-438. http://dx.doi.org/10.1016/j.jff.2019.04.039.

Verma, N., Usman, K., Patel, N., Jain, A., Dhakre, S., Swaroop, A., Bagchi, M., Kumar, P., Preuss, H. G., \& Bagchi, D. (2016). A multicenter clinical study to determine the efficacy of a novel fenugreek seed (Trigonella foenum-graecum) extract (Fenfuro ${ }^{\mathrm{rm}}$ ) in patients with type 2 diabetes. Food \& Nutrition Research, 60(1), 32382. http:// dx.doi.org/10.3402/fnr.v60.32382. PMid:27733237.

Willey, V. J., Kong, S., Wu, B., Raval, A., Hobbs, T., Windsheimer, A., Deshpande, G., Tunceli, O., Sakurada, B., \& Bouchard, J. R. (2018). Estimating the real-world cost of diabetes mellitus in the United States during an 8 -year period using 2 cost methodologies. American Health \& Drug Benefits, 11(6), 310-318. PMid:30464797.

Williams, R., Karuranga, S., Malanda, B., Saeedi, P., Basit, A., Besançon, S., Bommer, C., Esteghamati, A., Ogurtsova, K., Zhang, P., \& Colagiuri, S. (2020). Global and regional estimates and projections of diabetes-related health expenditure: results from the International Diabetes Federation Diabetes Atlas. Diabetes Research and Clinical Practice, 162, 108072. http://dx.doi.org/10.1016/j.diabres.2020.108072. PMid:32061820.

Zare, R., Nadjarzadeh, A., Zarshenas, M. M., Shams, M., \& Heydari, M. (2019). Efficacy of cinnamon in patients with type II diabetes mellitus: a randomized controlled clinical trial. Clinical Nutrition, 38(2), 549-556. http://dx.doi.org/10.1016/j.clnu.2018.03.003. PMid:29605574. 